\title{
PENGARUH PENERAPAN PEMBELAJARAN BERBASIS PENGALAMAN MENGGUNAKAN PERCOBAAN SECARA INKUIRI TERHADAP PENINGKATAN KETERAMPILAN PROSES SAINS SISWA SEKOLAH DASAR PADA PEMBELAJARAN IPA Oleh: \\ Meri Yusup ${ }^{1}$, Andi Suhandi \\ Universitas Pendidikan Indonesia
}

\begin{abstract}
The effect of the application of experience-based learning to increase understanding and science process skills of elementary school students in learning science. This study aimed to determine the effect of the use of experience-based learning that uses inquiry and experimental trials of traditional (verification) in science teaching in elementary school to the improvement of Science Process Skills students on a simple plane material in class V. This study uses quasi-experimental. Based on the results of the N-gain calculation Science Process Skills for the experimental class of 0.44 with the category of Medium and the control grade of 0.08 with the low category.
\end{abstract}

Keywords: Experience Based Learning, Science process skills, Science Education

\begin{abstract}
Abstrak: Pengaruh penerapan pembelajaran berbasis pengalaman terhadap peningkatan kemampuan memahami dan keterampilan proses sains siswa sekolah dasar pada pembelajaran IPA. Penelitian ini bertujuan untuk mengetahui pengaruh penggunaan pembelajaran berbasis pengalaman yang menggunakan percobaan secara inkuiri maupun percobaan tradisional (verifikatif) dalam pembelajaran IPA di Sekolah Dasar (SD) terhadap peningkatan Keterampilan Proses Sains (KPS) siswa pada materi pesawat sederhana di kelas V. penelitian ini menggunakan kuasi eksperimen. Berdasarkan hasil perhitungan N-gain Keterampilan Proses Sains untuk kelas eksperimen sebesar 0,44 dengan katagori Sedang dan pada kelas kontrol sebesar 0,08 dengan katagori rendah.
\end{abstract}

Kata Kunci : Pembelajaran Berbasis Pengalaman, Keterampilan proses Sains, IPA

\section{PENDAHULUAN}

Ilmu Pengetahuan Alam (IPA) merupakan salah satu pelajaran yang ada disetiap jenjang sekolah. IPA merupakan pelajaran yang membahas alam semesta beserta isinya. Pada hakikatnya, pembelajaran menurut Sulistriyoni (2007) IPA terdiri dari tiga segi yang saling berkaitan dan tidak dapat dipisahkan yaitu segi produk, segi proses, dan segi sikap. Ketiga hal tersebut harus muncul dalam pembelajaran IPA. Dari segi produk siswa diharapkan dapat memahami konsepkonsep IPA dan keterkaitannya dengan kehidupan sehari-hari, dari segi proses siswa diharapkan dapat memahami konsep yang diperolehnya untuk menjelaskan masalah dan memecahkan masalah dalam kehidupan sehari-hari, sedangkan dari segi sikap siswa diharapkan mempunyai minat untuk mempelajari benda-benda dilingkungannya, dari tiga segi tersebut dapat dikatakan bahwa dalam pembelajaran IPA, konsep didapat oleh siswa melalui proses dan proses yang dialami siswa tersebut bertujuan untuk mengembangkan sikap pada diri siswa. Oleh karena itu guru dalam membelajarkan IPA tidak boleh menitik beratkan pada salah satu segi saja seperti produk, namun juga harus memperhatikan segi proses ketika siswa melakukan pelajaran. Dalam bagian proses maka akan terlihat keterampilan-keterampilan yang dimiliki siswa.

Menurut Sanjaya (2008) Salah satu masalah yang terdapat didunia pendidikan kita yaitu masalah lemahnya proses pembelajaran. Banyak siswa yang belum mampu mengembangkan pemahamannya terhadap konsep tertentu.

\footnotetext{
${ }^{1}$ Universitas Garut, Email: meriyusup@gmail.com
} 
Karena antara perolehan pengetahuan dan prosesnya tidak terintegrasi dan tidak memungkinkan siswa untuk menangkap makna secara fleksibel. Sebagai contoh, siswa mampu menghapalkan berbagai konsep, fakta, namun tidak dapat menggunakannya untuk menjelaskan fenomena dalam kehidupan yang berhubungan dengan konsep dan fakta yang telah mereka hafal. Oleh karena itu sangat penting bagi guru untuk menekankan bagian proses dalam pembelajaran IPA.

Bagian proses IPA penting untuk dikuasai siswa di semua jenjang sekolah. Menurut Semiawan (Bundu,2006) bagian proses penting karena (1) perkembangan ilmu berlangsung cepat sehingga tidak mungkin lagi untuk mengaarka fakta dan konsep, (2) siswa akan lebih mudah memahami konsep yang abstrak apabila belajar melalui benda-benda kongkrit dan langsung melakukannya sendiri, (3) penemuan ilmu pengetahuan sifat kebenarannya relatif, dan (4) dalam proses belajar mengajar pengembangan konsep tidak bisa dipisahkan dari pengembangan sikap dan nilai. Keterampilan proses akan menjadi jembatan antara pengembangan konsep dan pengambangan sikap. Keterampilan proses dalam pembelajaran IPA dapat diartikan sejumlah keterampilan yang harus dimiliki siswa untuk dapat mengkaji fenomena yang terdapat di alam dengan cara-cara tertentu untuk memperoleh ilmu tersebut dan berguna dalam pengembangan ilmu tersebut untuk kedepannya (Bundu, 2006). Dengan menguasai keterampilan proses ini diharapkan siswa dapat mempelajari IPA sebagaimana para ahli lakukan yakni dengan mengobservasi, klasifikasi, aplikasi konsep, prediksi, interpretasi, menggunakan alat, eksperimen, mengkomunikasikan, dan mengajukan pertanyaan. Untuk dapat menanamkan keterampilan proses ini kepada siswa diperlukan model-model pembelajaran yang mendukung.
Model pembelajaran yang dapat mendukung dikuasainya keterampilan proses tentu pembelajaran yang menekankan kegiatan berpusat pada siswa. Hal ini bertujuan agar siswa lebih banyak melakukan kegiatan sehingga siswa dapat melatih keterampilan proses yang dimilikinya. Selain itu, model yang digunakan haruslah memiliki kegiatan yang dapat memunculkan keterampilanketerampilan proses. Melalui hal tersebut pembelajaran akan dapat mengoptimalkan potensi yang dimiliki siswa, sehingga diharapkan keterampilan yang dikuasai siswa dapat menjadi sikap yang diterapkan siswa dalam kehidupan sehari-harinya. Salah satu model yang dapat diterapkan untuk mengembangkan keterampilan proses yaitu model pembelajaran berbasis pengalaman.

Model pembelajaran eksperiensial merupakan model pembelajaran yang berbasiskan pengalaman yang dikembangkan oleh David Kolb yang dikemas dalam sebuah buku dengan judul Experiential Learning: Experience as a Source of Knowledge and Development (Kolb, 1984). Secara lebih rinci kerangka pikir Experiential Learning atau pembelajaran berbasis pengalaman itu terdiri atas (1) concrete experinece, (2) reflective observation, (3) abstract conceptualization, dan (4) active experimentation. Didalam kegiatan pembelajaran berbasis pengalaman konsep yang diberikan pada siswa dikaitkan dengan pengalaman yang telah dirasakan atau dilihat oleh siswa yang kemudian diterapkan didalam pembelajaran melalui kegiatan percobaan hal ini diharapkan akan menghasilkan pemahaman dan keterampilan proses siswa meningkat dalam pembelajaran IPA.

\section{METODOLOGI PENELITIAN}

Metode yang digunakan dalam penelitian ini adalah eksperimen semu. Pelaksanaan pembelajaran dengan model 
pembelajaran berbasis pengalaman menggunakan percobaan secara inkuiri kemudian dilihat pengaruhnya terhadap peningkatan keterampilan proses sains siswa pada kelas eksperimen.

Desain penelitian yang digunakan dalam penelitian ini yaitu "Matching Only Pretest Posttest Control Group Design”. Desain ini melibatkan dua kelompok sampel, yaitu kelompok eksperimen dan kelompok kontrol yang dipilih tanpa melalui random sampling. Keterampilan proses sains kedua kelompok di ukur dua kali, yaitu pada saat pretest dan posttest. Pretest dilakukan untuk mengetahui kemampuan awal siswa apakah terdapat tersebut. Sedangkan hasil posttest digunakan untuk melihat hasil dari kedua kelompok siswa baik itu kelas eksperimen maupun kontrol yang kemudian dibandingkan untuk membuktikan adanya perbedaan tingkat kemampuan memahami dan keterampilan proses sain siswa, adapun hasil yang diharapkan yaitu tidak adanya perbedaan tingkat keterampilan proses sains siswa dari kedua kelompok tersebut. Pretest dan posttest terhadap kedua kelompok dilakukan dengan menggunakan instrumen yang sama (Sugiyono 2011; Freankel dan Wallen 2007; Creswell 2008). Desain penelitian yang digunakan di tampilkan dalam Tabel

Tabel 1. Desain Penelitian The Matching-Only Pretest-Posttest Control Group Design

\begin{tabular}{|l|c|c|c|}
\hline Kelompok & Pretest & Perlakuan & Posttest \\
\hline eksperimen & $\mathrm{O}_{1}, \mathrm{O}_{2}$ & $\mathrm{X}$ & $\mathrm{O}_{1}, \mathrm{O}_{2}$ \\
\hline kontrol & $\mathrm{O}_{1}, \mathrm{O}_{2}$ & $\mathrm{C}$ & $\mathrm{O}_{1}, \mathrm{O}_{2}$ \\
\hline
\end{tabular}

perbedaan di antara kedua kelompok

Keterangan:

$\mathrm{O}_{1}=$ Derajat kemampuan memahami siswa

$\mathrm{O}_{2}=$ Derajat keterampilan proses

sains siswa

$\mathrm{X}=$ Penerapan pembelajaran

berbasis pengalaman
1.

Instrumen untuk mengukur keterampilan proses sains terdiri dari 18 soal yang berbentuk pilihan ganda yang meliputi empat aspek keterampilan yaitu merumuskan percobaan, bertanya, merumuskan hipotesis dan memprediksi. Instrumen tes telah diuji kelayakannya

Tabel 2. Rekapitulasi Skor rata-rata Pretest, Posttest, dan N-Gain Keterampilan Proses Sains Siswa

\begin{tabular}{|c|c|c|}
\hline Kelas & Nilai & Rerata \\
\hline \multirow{2}{*}{ Eksperimen } & Pre test & 4,78 \\
\cline { 2 - 3 } & Post test & 9,84 \\
\hline \multirow{2}{*}{ Kontrol } & Pre test & 5,41 \\
\cline { 2 - 3 } & Post test & 6,44 \\
\hline Eksperimen & \multirow{2}{*}{ N-gain } & 0,44 \\
\cline { 3 - 3 } Kontrol & \multirow{2}{|c}{0,08} \\
\hline
\end{tabular}

menggunakan percobaan secara inkuiri

$\mathrm{C}=$ Penerapan pembelajaran berbasis pengalaman dengan menggunakan percobaan tradisional dengan reabilitas tes 0,762 dengan kriteria tinggi (Arikunto, 2007).

Analisis terhadap perbandingan keterampilan proses sains antara kelas eksperimen dan kelas kontrol dilakukan dengan uji beda rerata (uji hipotesis) pada $\mathrm{N}$-gain keterampilan proses sains siswa 
yang sebelumnya telah diuji normalitas dan homogenitasnya. Pengujian beda rerata ini dilakukan menggunakan bantuan piranti lunak pengolah data IBM SPSS Statistics 20.

\section{HASIL PENELITIAN DAN PEMBAHASAN}

Perbandingan peningkatan keterampilan proses sains pada materi pesawat sederhana antara kelas eksperimen dan kelas kontrol dapat dilihat pada tabel 2.

Perbedaan Peningkatan Keterampilan Proses Sains antara kelas eksperimen dan kelas kontrol digambarkan pada Gambar 1

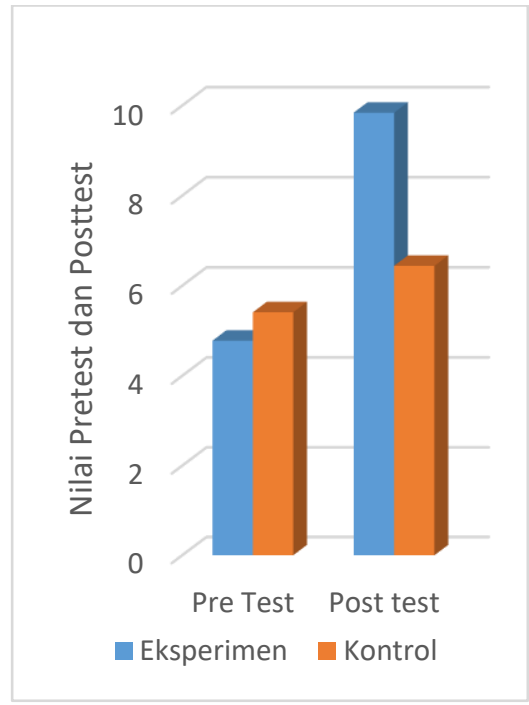

Adapun perbedaan peningkatan keterampilan proses sains antara kedua

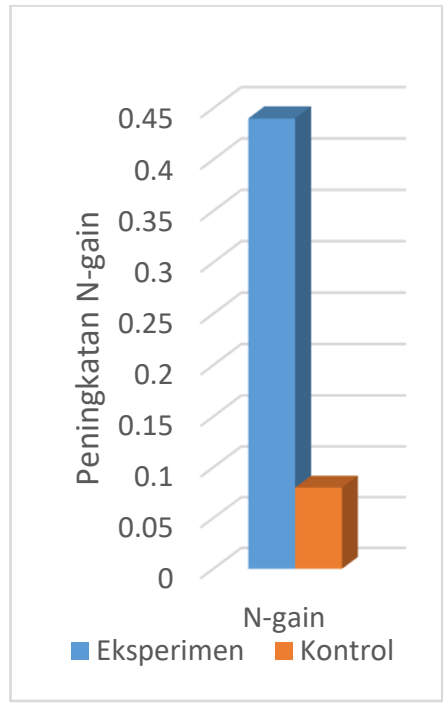

Gambar 1

Skor rata-rata Pretest, Posttest, dan N-Gain Keterampilan Proses Sains Siswa

kelas pada setiap aspek keterampilan proses sains dapat dilihat pada tabel 3 .

Tabel 3. Rerata N-gain Keterampilan Proses Sains Ditinjau Dari Setiap Aspek Pada Kedua Kelompok

\begin{tabular}{|l|c|c|c|c|}
\hline \multirow{2}{*}{$\begin{array}{c}\text { Aspek Keterampilan } \\
\text { Proses Sains }\end{array}$} & \multicolumn{2}{|c|}{ Kelas Kontrol } & \multicolumn{2}{c|}{ Kelas Eksperimen } \\
\cline { 2 - 5 } & $\begin{array}{c}\text { Rerata } \\
\text { N-gain }\end{array}$ & Katagori & $\begin{array}{c}\text { Rerata } \\
\text { N-gain }\end{array}$ & Katagori \\
\hline Merumuskan Percobaan & $-0,03$ & Negatif & 0,49 & Sedang \\
\hline Bertanya & 0,24 & Rendah & 0,34 & Sedang \\
\hline Merumuskan Hipotesis & 0,08 & Rendah & 0,42 & Sedang \\
\hline Memprediksi & 0,13 & Rendah & 0,47 & Sedang \\
\hline
\end{tabular}

Berdasarkan diagram pada gambar 1 dapat terlihat bahwa perolehan skor ratarata gain yang dinormalisasikan $\langle\mathrm{g}>$ untuk kelas eksperimen berkatagorikan sedang dan pada kelas kontrol berkatagorikan rendah. Hal ini disebabkan keterlaksanaan pembelajaran berbasis pengalaman menggunakan percobaan inkuiri dan verifikatif tidak terlaksana dengan maksimal (kriteria hampir seluruh kegiatan terlaksana). Namun demikian, secara kuantitas peningkatan keterampilan proses terlihat lebih tinggi dibandingkan dengan siswa pada kelas kontrol. 
Hasil pengujian beda rerata (uji hipotesis) terhadap skor rerata gain yang dinormalisasikan $\langle\mathrm{g}\rangle$ dapat disimpulkan bahwa pada taraf kepercayaan 0,65 (signifikansi 0,05) penggunaan pembelajaran berbasis pengalaman menggunakan percobaan secara inkuiri lebih meningkatkan keterampilan proses sains siswa pada pelajaran IPA dengan materi pesawat sederhana dibandingkan dengan pembelajaran berbasis pengalaman menggunakan percobaan verifikatif.

Hasil pengolahan dan analisis data di atas menunjukan bahwa penerapan pembelajaran berbasis pengalaman menggunakan percobaan secara inkuiri lebih efektif dalam meningkatkan keterampilan proses sains dibandingkan dengan pembelajaran berbasis pengalaman menggunakan percobaan secara verifikatif.

Lebih efektifnya pembelajaran berbasis pengalaman menggunakan percobaan secara inkuiri dibandingkan dengan pembelajaran berbasis pengalaman menggunakan percobaan verifikatif. Dahar (1996), belajar melalui proses mencari dan menemukan memungkinkan siswa untuk menggunakan segala potensinya terutama proses mentalnya untuk menemukan suatu konsep atu prinsip. Senada dengan Dahar, Rustaman (2005 hal 79) menyatakan bahwa pengalaman belajar dengan menerapkan keterampilan proses sains yang dilakukan langsung oleh siswa membuat pembelajaran akan lebih bermakna. Jadi dapat disimpulkan bahwa jika ingin memahami pembelajaran IPA maka pembelajaran haruslah bermakna, dan pembelajaran bermakna itu adalah pembelajaran yang menerapkan keterampilan proses sains didalamnya dan salah satunya yaitu dengan pembelajaran berbasis pengalaman menggunakan percobaan inkuiri.

\section{KESIMPULAN}

Berdasarkan data dan analisis hasil penelitian yang telah dilakukan mengenai penerapan pembelajaran berbasis pengalaman menggunakan percobaan secara inkuiri untuk meningkatkan keterampilan proses sains dapat disimpulkan bahwa Pengaruh pembelajaran berbasis pengalaman menggunakan percobaan secara inkuri dapat lebih meningkatkan keterampilan proses sains dibandingkan pengaruh pembelajaran berbasis pengalaman menggunakan percobaan tradisional. Hal ini dibuktikan dengan perolehan $\mathrm{N}$-gain kelas eksperimen sebesar 0,44. Sedangkan pada kelas kontrol peningkatan $\mathrm{N}$-gainnya sebesar 0,08.

Berdasarkan hasil penelitian, maka peneliti memberikan saran sebagai berikut: 1) Bagi peneliti lain perlu dilakukan penelitian lebih lanjut mengenai penerapan pembelajaran berbasis pengalaman menggunakan percobaan secara inkuiri agar dapat terlihat hasil positif dari model ini. 2) Diharapkan dapat mengembangkan pembelajaran berbasis pengalaman menggunakan percobaan secara inkuiri pada materi atau konsep lain terutama materi yang bersifat nyata agar dapat di uji cobakan dalam kelas, sehingga pemahaman siswa dapat lebih meningkat. 3) Penambahan waktu pembelajaran untuk mengoptimalkan kegiatan pembelajaran berbasis pengalaman menggunakan percobaan secara inkuiri, dikarenakan pembelajaran ini membutuhkan porsi waktu yang lebih banyak.4) Jumlah media atau alat peraga yang sesuai dengan jumlah kelompok belajar siswa agar dapat membantu kelancaran dalam kegiatan belajar mengajar dengan model pembelajaran berbasis pengalaman, selain itu jumlah yang sesuai dapat memangkas waktu pembelajaran menjadi lebih effektif. 


\section{DAFTAR PUSTAKA}

Arikunto, S. (2009). Dasar-Dasar Evaluasi Pendidikan. (Edisi Revisi). Jakarta: Bumi Aksara.

Bundu, P. (2006). Penelitian keterampilan Proses dan Sikap Ilmiah Dalam Pembelajaran Sains-SD. Jakarta:Departemen Pendidikan Nasional.

Creswell, John W (2013). Research Design Pendekatan Kualitatif Kuantitatif, dan Mixed. Yogyakarta. Pustaka pelajar.

Dahar, R.W (1996). Teori-Teori Belajar. Jakarta: Erlangga

Freankel, J.R Dan Wallen, N.E (2007). How to Design and Evaluate research in Education. (Six Edition). New York: Mc Graw Hill.

Rustaman, N (2005). Strategi Belajar Mengajar Biologi. Malang: Universitas Negeri Malang.

Sanjaya, Wina (2008). Strategi Pembelajaran Berorientasi Standar Proses Pendidikan. Jakarta: Kencana

Sugiyono. (2011). Metode Penelitian Pendidikan Pendekatan Kuantitatif, Kualitatif, dan R\&D. Bandung: Alfabeta

Suliatyorini, S. (2007). Model pembelajaran IPA Sekolah Dasar. Semarang: Tiara Wacana 